\title{
The International Society for Scientometrics and Informetrics Conference (ISSI) comes to South Africa. Report on the I I th ISSI International Conference, Madrid (Spain) June 25th-27, 2007
}

\author{
Dennis N. Ocholla \\ Department of Library and Information Science \\ University of Zululand, South Africa \\ docholla@pan.uzulu.ac.za
}

\section{Introduction}

Although the term informetrics has become increasingly popular, scientometrics, informetrics, bibliometrics and webometrics are all closely related or interlinked, as they could all be employed for quantitative analysis or measurement of all forms of recorded information in pure, applied and action research by studying their distribution,circulation and use pattern largely within or among individuals, disciplines, organisations or countries, for informing research, political,economic, scientific and technological issues, and knowledge policies and decisions, to name a few. Since 1940 informetrics has flourished and become a major sub-discipline within information science. There is a strong overlap between informetrics, bibliometrics,scientometrics, cybermetrics and webometrics, as illustrated by Bjorneborn and Ingwersen (2004) and also reflected by Ocholla and Onyancha (2005). The role of the International Society for Scientometrics (ISSI), as it is widely understood, is to spearhead research, scholarly exchange and dissermination of bibliometrics, scientometrics, webometrics and informetrics information. The "Time Line of Bibliometrics" is provided by Rousseau( 2002), Hertzel (1987), Hood and Wilson( 200I) as well as ISI (see http://www.isinet.com/isi/about/ timeline.html). A large part of publications in this domain are largely published in Scientometrics and the Journal of Informetrics. Examples of recent informetric studies published in South African Journal of Libraries and Information Science are found in vol.73(I\&2), 72(I,2\&3), $7 \mathrm{I}(3)$ and 70(2)

This report is informed by my recent participation in the $\mathrm{I}^{\text {th }}$ ISSI conference in Madrid (Spain) in June, where we (joint paper with Bosire Onyancha) presented our full paper entitled "Is HIV/AIDs in Africa Distinct? What can we learn from an analysis of the literature". At this occasion I was privileged to bid for hosting the $13^{\text {th }}$ ISSI conference in South Africa. The decision to bid for the conference was largely based on previous support and encouragement that we (together with Dr. Daisy Jacobs) received from colleagues and friends from South Africa.

\section{South Africa wins the bid for ISSI conference}

South Africa has won the bid to host the $13^{\text {th }}$ ISSI International conference in $201 \mathrm{I}$, to be held in Durban. This will be the first time the conference will be held on African soil. ISSI meets regularly bi-annually. Previous ISSI conferences took place in Belgium (1987), Canada (1989), India (1991), Germany (1993), USA (1995), Israel (1997), Mexico (1999), Australia (200I), China (2003), Sweden (2005), and Spain (2007). The II th ISSI conference in Madrid was competently organised by the Centre for Scientific Information and Documentation (CINDOC) of the Spanish Research Council (CSIC), in collaboration with several Information Science Departments from Spanish universities, and under the auspices of the International Society for Scientometrics and Informetrics (ISSI).

\section{Conference organisers}

The three Conference Chairs, all from CINDOC-CSIC, Madrid (Spain) were: Professor Isabel Gómez, Dr. María Bordons and Dr Isidro F. Aguillo, while the Programme Chair was Dr. Henk Moed, from the Centre for Science \& Technology Studies (CWTS), Leiden University, Leiden (The Netherlands). The poster Chair was: Dr. Ed Noyons, from the Centre for Science \& Technology Studies (CWTS), Leiden University, Leiden (The Netherlands), while the Satellite Workshops Chair was Prof. Peter Ingwersen, who is well known in South Africa, from the Royal School of Library \& Information Science, Copenhagen, Denmark. The doctoral forum, which acts as the advisory body on doctoral research proposals, was chaired by: Dr. Rickard Danell, Umeå University, Umeå, Sweden and Dr. Birger Larsen, the Royal School of Library \& Information Science, Copenhagen, Denmark. The conference also gains substantially from regional coordinators that normally represent the five continents of the world. Regional Programme Chairs were: North America - Prof. Kate MacCain, Drexel University, Philadelphia, USA; Latin America - Prof. Jane Russell, National Autonomous University of Mexico (UNAM), Mexico City, Mexico; Australia / Pacific - Dr. Linda Butler, The Australian National University, Canberra ACT, Australia; China / Far East - Prof. Liming Liang, Henan Normal University, Xinxiang, China; Europe / Africa - Prof. Peter Ingwersen, Royal School of Library \& Information Science, Copenhagen, Denmark; and India / Middle East - Prof. Ravichandra Rao, Indian Statistical Institute, Bangalore, India. 
There were five local committee members, six from CINDOC-CSIC, and one from Universidad Carlos III de Madrid and Universidad de Alcalá, Alcala de Henares, Spain. Fifty nine International Scientific Committee members drawn from all five continents and over 30 countries, including South Africa, participated largely in reviewing the submitted conference papers.

\section{Madrid as venue}

The venue of the II th $I S S I$ International conference was Madrid, the Capital of Spain, with its proliferation of Goya, Velasquez and Picasso, who rightly express the historical turbulence and passion of the region in their art. Present day Madrid is beautiful, and though modern, still pays homage to its artists and cultural practices, as reflected in the preservation of extraordinary medieval architecture, boulevards and cathedrals, which sit comfortably with the more modern or 'avant-garde'. The city is entrenched in its citizens, a warm and proud people, who made our stay there both comfortable and endlessly entertaining.

\section{The conference programme}

The conference focused largely on scientometrics, informetrics, bibliometrics, and webometrics. The objective of this conference was to bring together experts, members of ISSI and people interested in scientometrics and informetrics together to share knowledge on scientometrics and informetrics theories and new developments, and to popularise the discipline. Two hundred and fifty two participants from 36 countries took part in this conference. The conference papers stemmed from the following eighteen sub-themes:

- Dynamics of scientific fields. Growth and diversification

- Mapping and visualisation of knowledge

- Interdisciplinary - multidisciplinarity

- History of Bibliometrics and Scientometrics

- Mathematical modeling of informetric laws

- Citation and web link analysis

- Webometrics

- Collaboration in research (individual, institutional, regional, international)

- Evaluation of research performance: macro, meso and micro-levels

- Institutional and national publication productivity

- Development and comparative analyses of new indicators for Science and Technology

- Patent indicators

- Science policy analysis and forecasting

- Economic and social factors in information production and dissemination

- Scientometric impact of the Open Access initiatives

- New bibliometric indicators applied to digital libraries and e-journals

- Communication practices and performance assessment in Social Sciences and Humanities

- Effects of the use of bibliometric indicators on scientists, journal publishers and editors

The pre-conference, held on the $24^{\text {th }}$ June, was dedicated to a Doctoral Forum that uses experts in the discipline to discuss, help and advise doctoral students selected from all over the world in the field of scientometrics and informetrics, on how to develop their research proposals. Twelve students participated in the forum. The period $25^{\text {th }}-28^{\text {th }}$ of June was dedicated to the main conference on the highlighted themes. Out of the 250 submitted papers for review, 108 (43\%) were accepted for presentation as full papers (56), research in progress( 33) and posters (75). The post-conference Workshops: June 28th was dedicated to two themes: Methodological Issues in Using Curricula Vitae for Research Evaluation and Science Policy Analysis and Taking CiteSpace to Science: New Applications to Visualisation Programming. Two volumes of conference proceedings consisting of over 974 pages emerged from this conference.

\section{Support for ISSI in South Africa}

There was strong support for the ISSI conference to be hosted in Africa (South Africa) for the first time in 20I I. In most ISSI conferences, strong support comes from National Research Councils and/or universities, and it was recognised that South Africa is a leading research producer in Africa and an emerging research leader from the developing world, particularly in the science and technology disciplines. In the field of information science (IS), scientometrics and informetrics research is growing and should soon find a strong base in IS research in the country if widely popularised. Unfortunately, South Africa, and for that matter Africa, has not had an opportunity to host this important conference, which would possibly have propelled research in the discipline in the country, and indeed in Africa. Evidently, a conference of this magnitude always encourages the growth of research and increased national and international collaboration and knowledge sharing in areas of bibliometrics, informetrics, scientometrics and webometrics. With the 
support of ISSI, and by organising the conference on African soil and in South Africa for the first time, we are convinced that we will be able to popularise research in the domain within the country and on the continent.

\section{ISSI 20 I I Conference readiness}

We have the following facilities already arranged for the conference:

Venue: The International Convention Centre (ICC), Durban, voted as "Africa's Leading Conference Centre" for the $6^{\text {th }}$ time by the World Travel Awards, will be used as the venue for the conference.

Accommodation: Very reasonable and affordable hotel rates are being offered by the city's leading hotels to ensure the comfortable stay of all delegates.

Support: Thus far, we have secured moral support in writing from over 10 institutions and organisations, which include the Mayor of Durban, CEO ICC Durban, six LIS Schools based at the University of Zululand, University of KwaZuluNatal, University of Western Cape, University of Cape Town and University of Pretoria in South Africa, and the ViceChancellor, University of Zululand.

Additionally, among others we intend to approach the following organisations/institutions for support:

- Department/Ministry of Education;

- Department /Ministry of Science and Technology;

- National Research Foundation (NRF); and

- Center for Scientific and Industrial Research (CSIR).

One question that will possibly be asked, is why Durban? Durban is considered to be Africa's leading conference destination; is a vibrant city with a harmonious blend of African, Asian and European culture, and is located in the historical Kingdom of the Zulu nation in the KwaZulu-Natal province that is a gateway to African culture in South Africa. Durban is also South Africa's only destination of tropical summers, with 320 sunny days a year. According to ICC website and confirmation I got experienced while visiting the site, the International Convention Centre (ICC) in Durban, is one of the most advanced conference facilities in the world. It is a purpose-built, fully air-conditioned centre with three convention halls, which are interlinked but separate. Moveable walls allow for a number of different venue configurations. Alternatively, the halls can be opened up to form one large venue, with enough seating for 5000 delegates or 7000 square metres of column free floor space.

Aside from all these arrangements, we have got an enthusiastic and able team of organisers and supporters both here in the province and in the University, in addition to a further twelve information [science] departments within Universities in South Africa.

\section{Conclusion}

I wish to acknowledge the support I received from the University of Zululand Research Committee, which enabled my participation in this conference, my co-author, Dr. Bosire Onyancha for the excellent paper we jointly produced for the conference, and the support and encouragement received from Prof. Peter Ingwersen, from the Royal School of Library and Information Science, Copenhagen, Denmark; Prof. Ronald Rousseau, ISSI President; and Dr. Henry Small, former ISSI President (until 2007). I believe us capable of hosting an excellent ISSI conference in 20I I. More information on the ISSI conference in Madrid, Spain, can be accessed on http://issi2007.cindoc.csic.es/.

\section{References}

Bjorneborn and Ingwersen. 2004. Towards a basic framework of webometrics. Journal of the American Society for Information Science and Technology, 55(14), 1216-1227

Hertzel .1987. Bibliometrics. History of the Development of ideas in statistical Bibliography or Bibliometrics. In: Kent, A \& Lancour, H.(Eds), Encyclopedia of Library and Information Science Vol. 42, I44-21 9

Hood, W.W. and Wilson, C.S. 200I. The literature of bibliometrics, scientometrics and informetrics. Scientometrics, 52(2), 29I314

Ocholla, D.N. and Onyancha, B.O. 2005. The marginalised knowledge: An informetric analysis of indigenous knowledge publications ( 1990-2004) South African Journal of Libraries and Information Science, Vol.7I (3), 247-259

Rousseau, R. 2002. Timeline of Bibliometrics. [Online] http://users.pandora.be/ronald.rousseau/htm/timeline of bibliometrics.html accessed I 5 July 2007. 